\title{
\begin{tabular}{l|l} 
pcori $).$ & PATIENT-CENTERED OUTCOMES RESEARCH INSTITUTE \\
RESEARCH SUMMARY
\end{tabular}
}

PROJECT INFORMATION

September 2018

\section{Comparing Methods to Make Research More Patient Centered}

Principal investigator

Consuelo Wilkins, MD, MS
Organization

Vanderbilt University Medical Center

\section{What was the research about?}

Currently many researchers get input on their research projects from other researchers. But researchers want their work to be more patient centered, or relevant to patients' preferences, needs, and values. To do this, researchers need a way to measure how patient centered a research project is. They also need ways to get input from patients and community members on research projects.

In this study, the research team created a scale with a set of questions to measure how patient centered input is on research projects. The team tested the scale to be sure it measured patient-centeredness reliably and accurately.

Then the research team compared two ways researchers could get input on their projects:

- Community Engagement Studio, or CE Studio, brings together patients and community members.

- Translational Studio, or T2 Studio, brings together researchers.

The team wanted to learn if there were differences in how patient centered input was from CE Studio and T2 Studio.

\section{What were the results?}

The scale the research team developed worked well to measure patient-centeredness of input on research projects.
Using the scale, the research teams found that the input from CE Studio was more patient centered than the input from T2 Studio.

\section{What did the research team do?}

To measure how patient centered input is on research projects, the research team created the PersonCenteredness of Research Scale, made up of a set of questions. To create the scale, the team made a list of features that would make a project patient centered. Next, the team created questions to find out if projects showed these traits. The team then tested and revised the questions.

The research team assigned 20 research projects to one of two groups by chance. The project teams were from Vanderbilt University and Meharry Medical College in Nashville, Tennessee, and they wanted input on making their projects patient centered. Teams in the first group received input using CE Studio. Teams in the second group received input using T2 Studio. In both CE Studio and T2 Studio, people gave input through one- to two-hour discussion sessions.

To measure the patient-centeredness of input given in both groups, the research team used the new PersonCenteredness of Research Scale. The team compared the patient-centeredness of the input projects received in the CE Studio group with the T2 Studio group.

Two members of community organizations helped design and conduct the study. 


\section{What were the limits of the study?}

This study looked at a small number of research projects. Results may differ with more projects. The research team looked only at if the input on research projects was patient centered. They didn't look at other things that may make a project patient centered, such as if patients were on the project team.

\section{How can people use the results?}

Researchers could use CE Studio to get patientcentered input on research projects. They could also use the Person-Centeredness of Research Scale to measure how patient-centered input is on a research project.

To learn more about this project, visit www.pcori.org/Wilkins149. 